\title{
Rnf2 knockdown reduces cell viability and promotes cell cycle arrest in gastric cancer cells
}

\author{
JINGFANG ZHANG $^{1 *}$, ZHENNI SUN $^{2 *}$, YAFEI HAN ${ }^{3}$, RUYONG YAO $^{3}$, LU YUE $^{2}$, YAN XU ${ }^{4}$ and JISHENG ZHANG \\ ${ }^{1}$ Department of Pathology, Taishan Medical University, Taian, Shandong 271000; ${ }^{2}$ Department of Oncology, \\ Qingdao Municipal Hospital, School of Medicine, Qingdao University, Qingdao, Shandong 266011; ${ }^{3}$ The Center of Medical \\ Research; ${ }^{4}$ Department of Nephrology; ${ }^{5}$ Key Laboratory, Department of Otolaryngology-Head and Neck Surgery, \\ The Affiliated Hospital of Qingdao University, Qingdao, Shandong 266003, P.R. China
}

Received November 23, 2015; Accepted January 26, 2017

DOI: $10.3892 / \mathrm{ol} .2017 .5868$

\begin{abstract}
Rnf2 is a fundamental component of the polycomb repressive complex land acts as the really interesting new gene finger E3 ligase, which is responsible for histone $2 \mathrm{~A}$ modification. Previous studies have shown that the ring finger protein 2 ( Rnf2) is overexpressed in various types of tumor and has a close association with tumor development. However, few studies have been carried out into the expression and biological function of Rnf 2 in gastric cancer cells. The present study measured the expression of Rnf2 in gastric cancer cells and normal epithelial gastric cells. The results demonstrate that Rnf2 is upregulated in gastric cancer cells. In addition, the knockdown of Rnf2 inhibited the cell viability and induced increased G1 phase followed by a substantial reduction of the $\mathrm{G} 2 / \mathrm{M}$ phase. The expression levels of p21 and p27 were also significantly elevated by the knockdown of Rnf2. These results provide evidence of the oncogenic function of Rnf 2 in gastric cancer, possibly through an inhibition of cellular proliferation and a delay of the G2/M phase. Therefore, Rnf2 may be a novel target for the prognosis and therapy of gastric cancer.
\end{abstract}

Correspondence to: Professor Jisheng Zhang, Key Laboratory, Department of Otolaryngology-Head and Neck Surgery, The Affiliated Hospital of Qingdao University, 16 Jiangsu Road, Qingdao, Shandong 266003, P.R. China

E-mail: zhangjisheng76@hotmail.com

Professor Jingfang Zhang, Department of Pathology, Taishan Medical University, 619 Changcheng Road, Taian, Shandong 271000, P.R. China

E-mail: zhangjingfang99@163.com

*Contributed equally

Abbreviations: Rnf2, ring finger protein 2; H3K27me3, trimethylation of histone $\mathrm{H} 3$ at Lys27; PC, polycomb; PcG, polycomb group; $\mathrm{PH}$, polyhomeotic; $\mathrm{PRC1}$, polycomb repressive complex 1

Key words: Rnf2, cell cycle, gastric cancer

\section{Introduction}

Polycomb group (PcG) proteins are epigenetic regulators for gene silencing at the transcription level, acting as important regulators of DNA repair, proliferation, embryonic differentiation and cell-fate maintenance during development and in adult tissue homeostasis (1-3). These proteins exist in at least two biochemically and functionally distinct PcG core complexes referred to as polycomb repressive complex (PRC) 1 and 2. PRC2, which is involved in the initiation of gene repression, mediates the trimethylation of histone $\mathrm{H} 3$ at Lys27 (H3K27me3) and consists of histone methyltransferase enhancer of zeste homolog 2 (EZH2), the polycomb repressive complex and embryonic ectoderm development $(4,5)$. The mammalian PRC1, which is an ubiquitin E3 ligase complex, consists of polycomb (PC), polyhomeotic (PH), BMI1, ring finger protein (Rnf) $1 \mathrm{~A}$ and 2 (Rnf2) (6), among which Rnf2 has been identified as the catalytic subunit (7).

Rnf2, acts as the RING finger E3 ligase responsible for $\mathrm{H} 2 \mathrm{~A}$ modification in the PRC1 complex and influences early development and embryonic stem cell maintenance as well as cancer development $(8,9)$. Recent evidence showed that Rnf2 is highly expressed in various types of tumor in comparison to normal tissue counterparts (10). Knockdown of Rnf2 in HeLa cells resulted in morphological changes and an inhibition of cellularproliferation (7), suggesting an oncogenic function of Rnf2. Additionally, it has been reported that Rnf2 can either directly or indirectly target a distinct, specific pathway involved in cell cycle control $(11,12)$. However, in order to acquire a complete understanding of the mechanisms through which cancer progression is regulated by Rnf2, additional investigation is required.

Normal cell cycle progression is tightly controlled by a variety of molecular checkpoints, which supervise the biological processes that take place in different phases of the cell cycle (13). Progression through the cell cycle is governed by a family of cyclin-dependent kinases (CDKs), whose activity is regulated by phosphorylation, cyclin binding, the inhibitor of the CDK4 (INK4) family (p16INK4A, p15INK4B, p18 and p19) and kinase inhibitor protein (KIP) family (p21, p27 and p57) (14-16). p21 and p27 are the fundamental members of the KIP family and mediate various biological activities, 
primarily by binding to and inhibiting the kinase activity of the CDKs (17).

As a proliferation inhibitor, p21 performs an essential role in growth arrest following DNA damage, and overexpression of p21 leads to G1 and G2 or S-phase arrest $(18,19)$. PcG proteins can behave as integrators and/or modulators of cell cycle checkpoints in dividing cells. In mammals, PRC1 and PRC2 bind to and repress the INK4a/ARF locus, which encodes several proteins involved in cell cycle regulation including p14ARF and p16INK4A (20,21). In melanoma cells, EZH2 depletion induced a decrease in the proportion of cells in $\mathrm{S}$ phase with a concomitant increase of cells in the G1 phase as well as an elevated expression of p21 (22), indicating that PcG has close associations with p21 in regulating the cell cycle. However, the precise mechanism behind this remains unclear. The present study aimed to investigate the expression of Rnf2 and further explore its effect on cell viability and the cell cycle of gastric cancer (GC) cells.

\section{Materials and methods}

Cell culture. The human stomach cancer SGC-7901 cell line and normal gastric epithelium GES-1 cell line were obtained from the Central Laboratory of The Affiliated Hospital of Qingdao University (Qingdao, China). The cell lines were cultured in RPMI 1640 (Invitrogen; Thermo Fisher Scientific, Inc., Waltham, MA, CA, USA) supplemented with $10 \%$ fetal bovine serum (Invitrogen; Thermo Fisher Scientific, Inc.) and $1 \%$ penicillin/streptomycin under standard culture conditions (5\% $\mathrm{CO}_{2}, 37^{\circ} \mathrm{C}$ and $95 \%$ humidity). Human cell line assays were conducted according to IRB regulations at The Affiliated Hospital of Qingdao University.

Reverse transcription-quantitativepolymerase chain reaction (RT-qPCR). Total RNA was isolated using the TRIzol Reagent (Invitrogen; Thermo Fisher Scientific, Inc.) according to the manufacturer's protocol. A random-primed cDNA was generated using a Superscript II reverse transcription kit (Invitrogen; Thermo Fisher Scientific, Inc.). Triplicate reactions of cDNA amplification were performed in SYBR Premix Ex Taq (Takara Biotechnology Co. Ltd., Dalian, China) and analyzed using a 7900HT Fast Real-Time PCR System (Applied Biosystems; Thermo Fisher Scientific, Inc.). Relative expression levels were normalized using GAPDH and calculated using the $2^{-\Delta \Delta C q}$ method (23). A negative control without reverse transcriptase enzyme treatment was used. All experiments were repeated 3-4 times. Primer sequences are summarized as follows: p21-sense, 5'-CCATGTGGACCT GTCACTGT-3' and antisense, 5'-CGGCGTTTGGAGTGG TAGAA-3'; p27-sense, 5'-TAAGGAAGCGACCTGCAA CC-3' and antisense, 5'-TCTGAGGCCAGGCTTCTTG-3'; p16INK4A sense, 5'-CCGAATAGTTACGGTCGGAG-3' and antisense, 5'-CGGGTCGGGTGAGAGTGG-3'; p14ARF sense, 5'-CTGTGGCCCTCGTGCTG-3' and antisense, 5'-CAGCAGCTCCGCCACTC-3'; Rnf2 sense, 5'-TTCAGG CCTCATCCCACACT-3' and antisense, 5'-CAGCAGCTC CGCCACTC-3'; GAPDH sense, 5'-TCGACAGTCAGCCGC ATCTT-3' and antisense, 5'-GAGTTAAAAGCAGCCCTG GTG-3'.
Western blotting assay. SGC-7901 and GES-1 cells were washed with 1X PBS and pelleted at $600 \mathrm{x} \mathrm{g}$ for $5 \mathrm{~min}$ at $4^{\circ} \mathrm{C}$ and then lysed in $2 \%$ SDS lysis buffer (2\% SDS, $240 \mathrm{mM}$ Tris $\mathrm{pH}$ 6.8, and $10 \%$ glycerol). Proteins extracted from cells in log-phase growth were separated by $10 \%$ SDS-PAGE and transferred to polyvinylidene difluoride membranes (EMD Millipore, Billerica, MA, USA) using a semidry transfer system (Bio-Rad Laboratories, Inc., Hercules, MA, USA). Primary antibodiesdirected against $\beta$-Tubulin (\#AT809; 1:3,000; Beyotime Institute of Biotechnology, Haimen, China), Rnf2 (\#5694) p21 (\#2946), p27 (\#2552) (all 1:3,000; all Cell Signaling Technologies, Inc., Danvers, MA, USA) were incubated in TBS ( $\mathrm{pH} 7.4$ ) with $0.1 \%$ Tween 20 (TBST) and 5\% nonfat milk (Bio-Rad Laboratories, Inc.) with gentle agitation overnight at $4^{\circ} \mathrm{C}$ according to the manufacturer's protocol. Subsequent to washing 3 times with TBST, the membranes were incubated with horseradish peroxidase-conjugated secondary antibodies (\#SC-2357 and \#SC-516102; 1:10,000; Santa Cruz Biotechnology, Inc., Dallas, TX, USA) for $1 \mathrm{~h}$ at room temperature. The membranes were then washed again in TBST and visualized using an enhanced chemiluminescence kit (EMD Millipore). $\beta$-tubulinwas used as an internal reference. The experiments were repeated 3 times.

Cell counting kit $8(C C K-8)$ assay. Cell proliferation was quantified with a CCK-8 assay (Dojindo Molecular Technologies, Inc., Kumamoto, Japan). Cells were seeded in 96-well culture plates at a density of $1 \times 10^{4}$ per well in $100 \mu \mathrm{l}$ fresh RPMI 1640 supplemented with 10\% fetal bovine serum (both Invitrogen; Thermo Fisher Scientific, Inc.). Subsequent to a $48 \mathrm{~h}$ culture at $37^{\circ} \mathrm{C}, 10 \mu \mathrm{l}$ of CCK-8 were added in each well and incubated at $37^{\circ} \mathrm{C}$ for $4 \mathrm{~h}$. Absorbance was measured at $450 \mathrm{~nm}$ using a microplate reader (Bio-Rad Laboratories, Inc.). The measurement for each sample was conducted in triplicate to certify the accuracy.

Flow cytometric analysis of cell cycle. Cells were seeded in 6-well plates at a density of $5 \times 10^{5}$ cells/well and then transfected with Rnf 2 small hairpin RNA (shRNA; sequence, CGAAGTCTACACAGTGAATTA) using Lipofectamine 3000 following the manufacturer's protocol (\#L3000015; Thermo Fisher Scientific, Inc.) and cultured in RPMI 1640 supplemented with $10 \%$ fetal bovine serum at $37^{\circ} \mathrm{C}$ for $48 \mathrm{~h}$. The cells were harvested with trypsin, fixed with $70 \%$ ice-cold ethanol, and stained with propidium oxide using a Cell Cycle Analysis kit (Beyotime Institute of Biotechnology) according to the manufacturer's protocol. Cell cycle distributions were then analyzed by FACScan (BD Biosciences, Franklin Lakes, NJ, USA) and the percentage of cells in G1, S, and G2/M phase was calculated and compared. Data represent the mean value derived from triplicate experiments.

Statistical analyses. All statistical analyses were carried out using SPSSversion 17.0 (SPSS, Inc., Chicago, IL, USA). All of the data are presented as the mean \pm standard deviation for at least 3 independent experiments. The significant differences between any of two groups were evaluated by one-way analysis of variance. $\mathrm{P}<0.05$ was considered to indicate a statistically significant difference. 

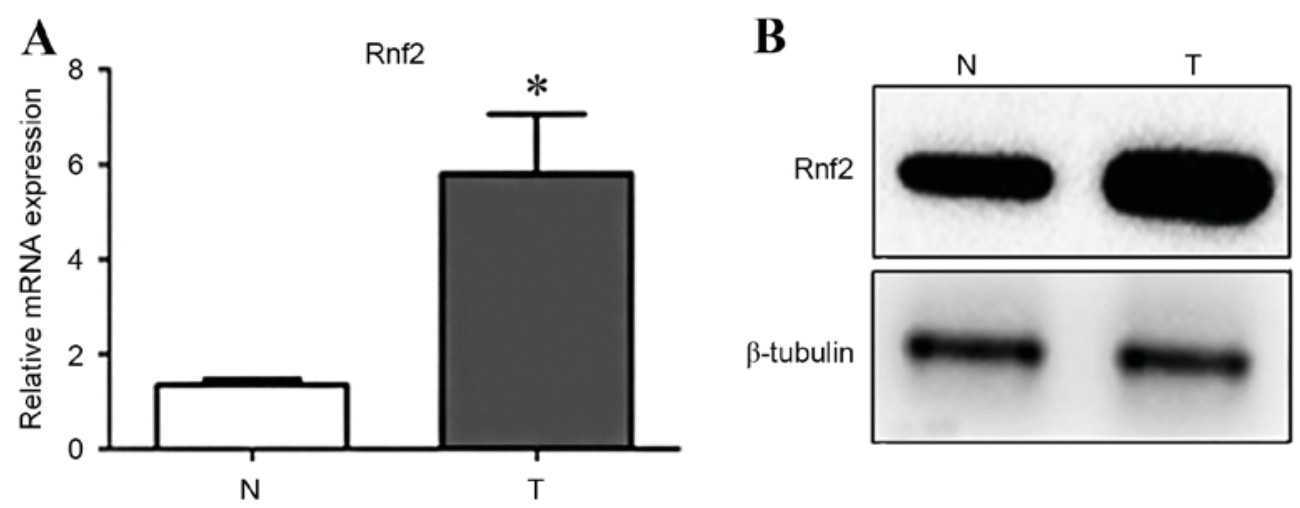

Figure 1. Expression of Rnf2 between the GC cells and normal epithelial gastric cells. (A) mRNA expression levels of Rnf2 in T is increased compared with N. (B) Western blot analysis demonstrates that the protein level of Rnf2 in T is increased compared with $\mathrm{N}$. $\beta$-tubulin was used as a control. " $\mathrm{P}<0.05$. Bars represent the mean, and error bars represent the standard deviation. Rnf2, ring finger protein 2; GC, gastric cancer; T, GC cells; N, normal epithelial gastric cells.

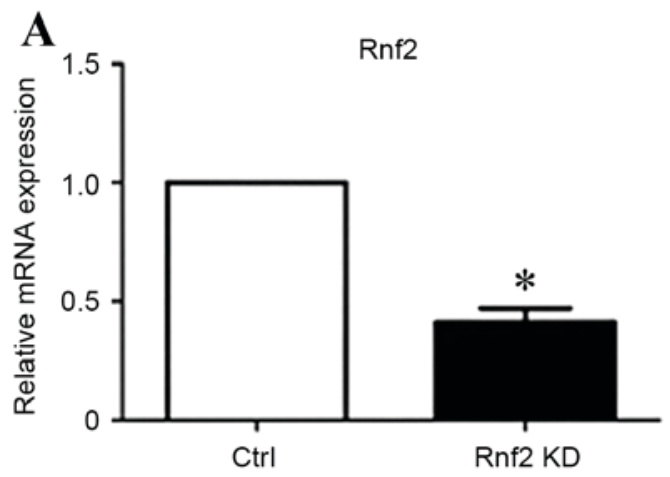

B
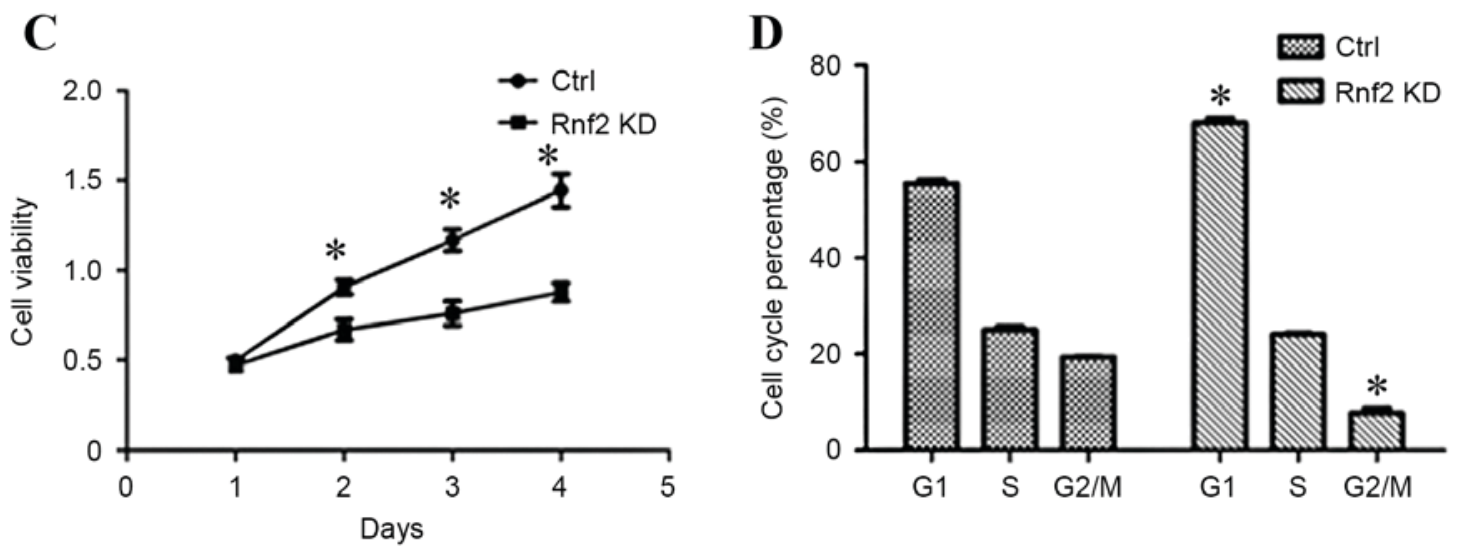

Figure 2. Knockdown of Rnf2 inhibited the viability of GC cells and induced G1 phase cell cycle arrest. (A) Expression of Rnf2 is significantly downregulated following Rnf2 shRNA transfection, as shown by reverse transcription-quantitative polymerase chain reaction. (B) Western blot analysis demonstrates the downregulation of Rnf2 following shRNA transfection. $\beta$-tubulin was used as a control. (C) The CCK-8 assay demonstrated that the knockdown of Rnf2 inhibited GC cell viability. (D) Cell cycle distribution of SGC-7901 following Rnf2 knockdown measured by propidium iodide staining and FACScan. ${ }^{*} \mathrm{P}<0.05$ vs. control. Bars represent the mean, and error bars represent the standard deviation. Rnf2, ring finger protein 2; GC, gastric cancer, shRNA, small hairpin RNA; KD, knockdown; CCK-8, cell counting kit-8.

\section{Results}

Rnf2 is overexpressed in GC cells. The present study first examined Rnf 2 expression in GC cells and normal gastric cells by RT-qPCR and western blot analysis. Results demonstrated that mRNA and protein levels of Rnf2 were significantly higher in GC cells compared with the normal gastric cells $(\mathrm{P}<0.05)$ (Fig. 1A and B).
Knockdown of Rnf2 inhibits viability and induces G1 cell cycle arrest in GC cells. To study the role of Rnf 2 in the progression of GC cells, the present study then investigated the knockdown of Rnf2 in SGC-7901 and whether Rnf2 influenced cell survival. RT-qPCR and western blot analysis demonstrated efficient knockdown of Rnf2 following transfection for $48 \mathrm{~h}$ (Fig. 2A and B). Accordingly, the viability of GC cells was suppressed upon silencing of Rnf2 (P<0.05; Fig. 2C). 

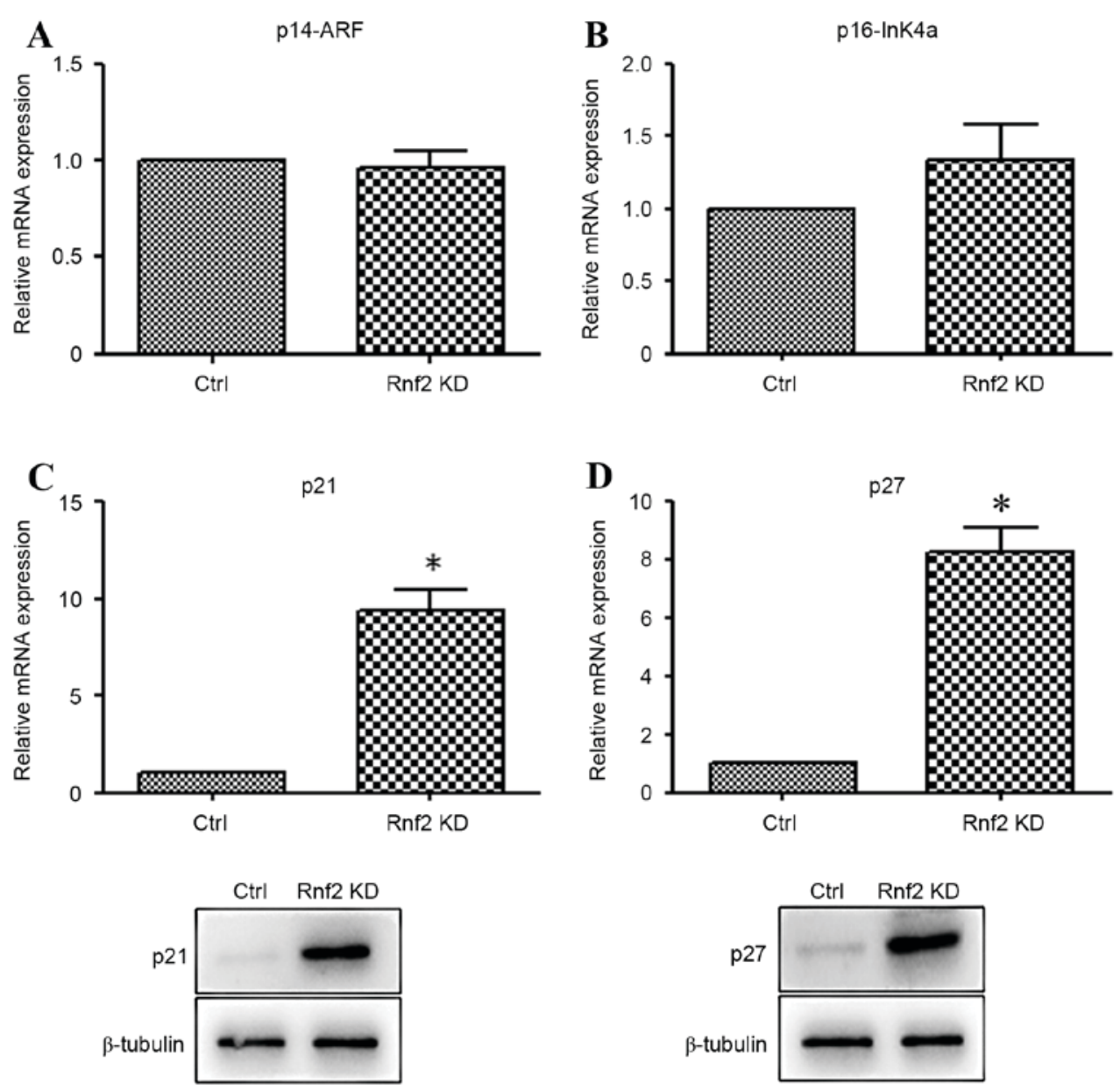

Figure 3. Cell cycle gene expression upon Rnf2 knockdown. mRNA expression levels of (A) p14-ARF and (B) p16-InK4ado not show significant differences between Rnf2 silenced GC cells and control cells. mRNA expression levels of (C) p21 and (D) p27 are significantly elevated in Rnf2 silenced GC cells compared with control cells. ${ }^{*} \mathrm{P}<0.05$. Bars represent the mean, and error bars represent the standard deviation. Rnf2, ring finger protein 2; p14-ARF, alternative reading frame protein 14; GC, gastric cancer; p16-InK4a, protein 16-cyclin dependent kinase inhibitor 2A; KD, knockdown.

Furthermore, knockdown of Rnf2 resulted in cell cycle arrest illustrated by increased percentage of cells in G1 phase and decreased percentage of cells in $\mathrm{G} 2 / \mathrm{M}$ phase ( $\mathrm{P}<0.05$; Fig. 2D).

Knockdown of Rnf2 increased the expression of $p 21$ and $p 27$. In order to further explore the probable mechanism of Rnf2 in the GC cells, the expression of p14, p16, p21 and p27 was detected by RT-qPCR and western blot analysis. As is demonstrated in Fig. 3A and B, there were no significant differences between the expression of p14 and p16. By contrast, the mRNA and protein levels of p21 and p27 were markedly increased in the Rnf2 silenced GC cells in comparison with the control cells $(\mathrm{P}<0.05)$ (Fig. 3C and D).

\section{Discussion}

The present study revealed that expression levels of Rnf2 are significantly increased in GC cells compared with their counterpart. Following the knockdown of Rnf2, GC cell viability was inhibited. Additionally, downregulation of Rnf2 blocked cell cycle progression by arresting cells in the G1 phase, which illustrates a unique activity of Rnf 2 in the proliferation of GC. To further investigate this mechanism, the present study examined the mRNA expression level of several cell cycle related genes. The results demonstrated that Rnf2 knockdown could notably induce the upregulation of $\mathrm{p} 21$ and $\mathrm{p} 27$, but the expression of p14 and p16 did not show the same tendency. Thus, the present study was a preliminary investigation into the function of Rnf2 in GC.

A major cause of cancer is through the dysregulation of proper transcriptional control, a process that is directly regulated by transcription factors, co-activators and co-repressors (24). Accumulating evidence indicates that the PC family of epigenetic proteins comprises transcriptional repressors that are often misregulated in various types of human cancer, and the expression level is associated with cancer progression (25), indicating that PcG proteins may exhibit oncogenic functions. Studies have identified that EZH2, which functions as a histone $\mathrm{H} 3$ methyltransferase, is involved in the progression of prostate cancer and in neoplastic transformation of breast epithelial cells $(26,27)$. Human BMI1 has been identified to be overexpressed in colorectal carcinoma (28), Hodgkin's lymphoma and diffuse large B-cell lymphoma (29). As for Rnf2, Sánchez-Beato et al (10) revealed that Rnf2 expression is higher in gastric and colonic tumors compared with the stomach or colon surface-epithelial cells. GC-derived, Burkitt's and Hodgkin's lymphoma also exhibited a higher level of Rnf2 expression (10). Results from the present study 
demonstrate that the expression of Rnf2 is higher in the GC cells compared with the normal gastric epithelial cells, which is in accordance with a previous study (10).

Rnf2, a core number of the PRC1 complex, is upregulated in several types of tumor and performs a critical role in tumor proliferation, immortalization and metastasis (30). A recent study has shown that the knockdown of Rnf2 significantly inhibits cell proliferation and colony formation in the colon cancer HCT116 cell line (31). In addition, it was also associated with induction of apoptosis by regulating MDM2 and p53 stability (31). Similarly, Su et al (9) reported that Rnf2 is essential for the proliferation of ovarian and testicular cancer cells by functioning as an E3 ligase for p53 degradation. However, to the best of our knowledge the role of Rnf 2 in the viability of GC has not been previously investigated. The current study revealed that downregulation of $\mathrm{Rnf} 2$ dramatically reduced the viability of GC cells. Additionally, downregulation of Rnf2 in GC cells induced increased G1 phase followed by a substantial reduction of G2/M (Fig. 2D), suggesting that Rnf2 is of vital important in regulating the growth of GC.

Considering the evidence that cellular proliferation is activated by cyclin-dependent kinases and inhibited in response to various stresses by corresponding inhibitors, including INK family and KIP family (32), the present study supposed that several tumor suppressors maybe involved in this process. The proteins p14 and p16 are alternative transcript variants of the INK4A-ARF (CDKN2A in humans) gene located on chromosome 9p21 and function as inhibitors of cell cycle progression, which possess complementary function as regulators of two major cell cycle control pathways, p53 and pRB, respectively $(33,34)$. The p16/pRB and p14/p53 cell cycle pathways are activated in the majority of human cancers, which suggests the importance of these pathways in repressing the process of carcinogenesis (35). p21 is a common element of the two pathways and may serve as a bridge between them $(36,37)$.

Previous studies demonstrated that p21 was regulated by p53-dependent and independent pathways (38). Rnf2 knockdown cells exhibited increased p21 expression and G1 phase in colon cancer HCT116 cell lines in an p53-dependent pathway, followed by marked accumulation of these cells at sub-G1 (39). Similar results have also been reported in hepatic cancer HepG2 cells (40). Additionally, p21 can act as a master effector of multiple tumor suppressor pathways on promoting anti-proliferative activities that are independent of the classical p53 tumor suppressor pathway. Subsequent tothe depletion of Ezh2 (a main component of PRC2), marked inhibition of cellular proliferation, G1 cell cycle arrest and accompanying upregulation of key cell-cycle regulators p16, p21 and p27 has been identified in lymphoma and tongue cancer $(41,42)$. However, the role of these proteins in regulating the GC cell proliferation and cell cycle has not previously been investigated. The present study demonstrated for the first time that p21 and p27 were elevated following the knockdown of Rnf2, while similar results were not shown in the mRNA level of p14 and p16. The reason of this discrepancy remains unclear and requires further exploration.

In conclusion, the present results established that Rnf 2 is overexpressed in GC cells and contributes to cell viability. Furthermore, knockdown of Rnf2 induced G1 phase cell cycle arrest and upregulation of p21 and p27. Therefore, the present findings may provide novel insights in the molecular mechanisms behind GC and provide new information that may be used in the prognosis and therapy of GC.

\section{Acknowledgements}

The study was supported by Shandong Provincial Education Department Program (grant no. J14LK02), the Natural Science Foundation of China (grant nos. 81672662, 81170688 and 81470973) and the Shandong Province Natural Science Foundation (grant no. ZR2014CM040).

\section{References}

1. Simon JA and Kingston RE: Mechanisms of polycomb gene silencing: Knowns and unknowns. Nat Rev Mol Cell Biol 10: 697-708, 2009.

2. Sparmann A and van Lohuizen M: Polycomb silencers control cell fate, development and cancer. Nat Rev Cancer 6: 846-856, 2006.

3. Bracken AP and Helin K: Polycomb group proteins: Navigators of lineage pathways led astray in cancer. Nat Rev Cancer 9: 773-784, 2009.

4. Cao R, Wang L, Wang H, Xia L, Erdjument-Bromage H, Tempst P, Jones RS and Zhang Y: Role of histone H3 lysine 27 methylation in Polycomb-group silencing. Science 298: 1039-1043, 2002.

5. Russell IF: Auditory perception under anaesthesia. Anaesthesia 34: 211, 1979.

6. Sanders LL: Gold therapy for rheumatoid arthritis. J Ark Med Soc 73: 135-137, 1976.

7. Wang H, Wang L, Erdjument-Bromage H, Vidal M, Tempst P, Jones RS and Zhang Y: Role of histone H2A ubiquitination in Polycomb silencing. Nature 431: 873-878, 2004.

8. Vidal M: Role of polycomb proteins Ring1A and Ring1B in the epigenetic regulation of gene expression. Int J Dev Biol 53: 355-370, 2009.

9. Su WJ, Fang JS, Cheng F, Liu C, Zhou F and Zhang J: RNF2/Ring $1 \mathrm{~b}$ negatively regulates $\mathrm{p} 53$ expression in selective cancer cell types to promote tumor development. Proc Natl Acad Sci USA 110: 1720-1725, 2013.

10. Sánchez-Beato M, Sánchez E, González-Carreró J, Morente M, Díez A, Sánchez-Verde L, Martín MC, Cigudosa JC, Vidal M and Piris MA: Variability in the expression of polycomb proteins in different normal and tumoral tissues. A pilot study using tissue microarrays. Mod Pathol 19: 684-694, 2006.

11. Wei M, Jiao D, Han D, Wu J, Wei F, Zheng G, Guo Z, Xi W, Yang F, Xie P, et al: Knockdown of RNF2 induces cell cycle arrest and apoptosis in prostate cancer cells through the upregulation of TXNIP. Oncotarget 8: 5323-5338, 2017.

12. Voncken JW, Roelen BA, Roefs M, de Vries S, Verhoeven E, Marino S, Deschamps J and van Lohuizen M: Rnf2 (Ring1b) deficiency causes gastrulation arrest and cell cycle inhibition. Proc Natl Acad Sci USA 100: 2468-2473, 2003.

13. Yagi A, Machii K, Nishimura H, Shida T and Nishioka I: Effect of aloe lectin on deoxyribonucleic acid synthesis in baby hamster kidney cells. Experientia 41: 669-671, 1985.

14. Morgan DO: Principles of CDK regulation. Nature 374: 131-134, 1995.

15. Sherr CJ: G1 phase progression: Cycling on cue. Cell 79: 551-555, 1994.

16. Reed SI, Bailly E, Dulic V, Hengst L, Resnitzky D and Slingerland J: G1 control in mammalian cells. J Cell Sci Suppl 18: 69-73, 1994.

17. Abbas T and Dutta A: p21 in cancer: Intricate networks and multiple activities. Nat Rev Cancer 9: 400-414, 2009.

18. Niculescu AB III, Chen X, Smeets M, Hengst L, Prives C and Reed SI: Effects of p21(Cip1/Waf1) at both the G1/S and the G2/M cell cycle transitions: $p R b$ is a critical determinant in blocking DNA replication and in preventing endoreduplication. Mol Cell Biol 18: 629-643, 1998.

19. Dulić V, Kaufmann WK, Wilson SJ, Tlsty TD, Lees E, Harper JW, Elledge SJ and Reed SI: p53-dependent inhibition of cyclin-dependent kinase activities in human fibroblasts during radiation-induced G1 arrest. Cell 76: 1013-1023, 1994. 
20. Maertens GN, El Messaoudi-Aubert S, Racek T, Stock JK Nicholls J, Rodriguez-Niedenführ M, Gil J and Peters G: Several distinct polycomb complexes regulate and co-localize on the INK4a tumor suppressor locus. PLoS One 4: e6380, 2009.

21. Jacobs JJ, Kieboom K, Marino S, DePinho RA and van Lohuizen M: The oncogene and Polycomb-group gene bmi-1 regulates cell proliferation and senescence through the ink4a locus. Nature 397: 164-168, 1999.

22. Fan T, Jiang S, Chung N, Alikhan A, Ni C, Lee CC and Hornyak TJ: EZH2-dependent suppression of a cellular senescence phenotype in melanoma cells by inhibition of $\mathrm{p} 21 / \mathrm{CDKN} 1 \mathrm{~A}$ expression. Mol Cancer Res 9: 418-429, 2011.

23. Livak KJ and Schmittgen TD: Analysis of relative gene expression data using real-time quantitative PCR and the 2(-Delta Delta C(T)) method. Methods 25: 402-408, 2001.

24. Yamamoto Y, Abe A and Emi N: Clarifying the impact of polycomb complex component disruption in human cancers. Mol Cancer Res 12: 479-484, 2014.

25. Wang W, Qin JJ, Voruganti S, Nag S, Zhou J and Zhang R: Polycomb group (PcG) proteins and human cancers: Multifaceted functions and therapeutic implications. Med Res Rev 35: 1220-1267, 2015.

26. Kleer CG, Cao Q, Varambally S, Shen R, Ota I, Tomlins SA, Ghosh D, Sewalt RG, Otte AP, Hayes DF, et al: EZH2 is a marker of aggressive breast cancer and promotes neoplastic transformation of breast epithelial cells. Proc Natl Acad Sci USA 100: 11606-11611, 2003.

27. Varambally S, Dhanasekaran SM, Zhou M, Barrette sTR, Kumar-Sinha C, Sanda MG, Ghosh D, Pienta KJ, Sewalt RG, Otte AP, et al: The polycomb group protein EZH2 is involved in progression of prostate cancer. Nature 419: 624-629, 2002.

28. Li DW, Tang HM, Fan JW, Yan DW, Zhou CZ, Li SX, Wang XL and Peng ZH: Expression level of Bmi-1 oncoprotein is associated with progression and prognosis in colon cancer. J Cancer Res Clin Oncol 136: 997-1006, 2010.

29. Garcia JF, Camacho FI, Morente M, Fraga M, Montalbán C, Alvaro T, Bellas C, Castaño A, Díez A, Flores T, et al: Hodgkin and reed-sternberg cells harbor alterations in the major tumor suppressor pathways and cell-cycle checkpoints: Analyses using tissue microarrays. Blood 101: 681-689, 2003.

30. Bosch A, Panoutsopoulou K, Corominas JM, Gimeno R, Moreno-Bueno G, Martín-Caballero J, Morales S, Lobato T, Martínez-Romero C, Farias EF, et al: The polycomb group protein RING1B is overexpressed in ductal breast carcinoma and is required to sustain FAK steady state levels in breast cancer epithelial cells. Oncotarget 5: 2065-2076, 2014.
31. Wen W, Peng C, Kim MO, Ho Jeong C, Zhu F, Yao K, Zykova T, Ma W, Carper A, Langfald A, et al: Knockdown of RNF2 induces apoptosis by regulating MDM2 and p53 stability. Oncogene 33: 421-428, 2014

32. Ortega S, Malumbres M and Barbacid M: Cyclin D-dependent kinases, INK4 inhibitors and cancer. Biochim Biophys Acta 1602: 73-87, 2002.

33. Pérez-Sayáns M, Suárez-Peñaranda JM, Gayoso-Diz P, Barros-Angueira F, Gándara-Rey JM and Garcia-Garcia A: p16 (INK4a)/CDKN2 expression and its relationship with oral squamous cell carcinoma is our current knowledge enough? Cancer Lett 306: 134-141, 2011.

34. Llanos S, Clark PA, Rowe J and Peters G: Stabilization of p53 by p14ARF without relocation of MDM2 to the nucleolus. Nat Cell Biol 3: 445-452, 2001.

35. Dominguez G, Silva J, Garcia JM, Silva JM, Rodriguez R, Muñoz C, Chacón I, Sanchez R, Carballido J, Colás A, et al: Prevalence of aberrant methylation of p14ARF over p16INK4a in some human primary tumors. Mutat Res 530: 9-17, 2003.

36. Cheng M, Olivier P, Diehl JA, Fero M, Roussel MF, Roberts JM and Sherr CJ: The p21(Cip1) and p27(Kip1) CDK 'inhibitors' are essential activators of cyclin D-dependent kinases in murine fibroblasts. EMBO J 18: 1571-1583, 1999.

37. Carnero A, Hudson JD, Price CM and Beach DH: p16INK4A and p19ARF act in overlapping pathways in cellular immortalization. Nat Cell Biol 2: 148-155, 2000.

38. Kerkhoff E and Rapp UR: Cell cycle targets of Ras/Raf signalling. Oncogene 17 (11 Reviews): 1457-1462, 1998.

39. Villabona C, Novials A, Soler J, Morató J, Gómez JM and Navarro MA: Hormonal evaluation of 27 patients with acromegaly. Med Clin (Barc) 84: 219-222, 1985 (In Spanish).

40. Sen N, Satija YK and Das S: PGC-1 $\alpha$, a key modulator of p53, promotes cell survival upon metabolic stress. Mol Cell 44: 621-634, 2011.

41. Fiskus W, Wang Y, Sreekumar A, Buckley KM, Shi H, Jillella A, Ustun C, Rao R, Fernandez P, Chen J, et al: Combined epigenetic therapy with the histone methyltransferase EZH2 inhibitor 3-deazaneplanocin A and the histone deacetylase inhibitor panobinostat against human AML cells. Blood 114: 2733-2743, 2009.

42. Li Z, Wang Y, Qiu J, Li Q, Yuan C, Zhang W, Wang D, Ye J, Jiang $\mathrm{H}$, Yang J and Cheng J: The polycomb group protein EZH2 is a novel therapeutic target in tongue cancer. Oncotarget 4: 2532-2549, 2013 